A comprehensive programme to study the avalanches was begun in 1967 on the basis of which avalanche protective works were undertaken in 1974-75 and their effectiveness analysed in 1976-77. Most of these depend on local material; the main rock deposits available are andesite, which has good permeability and is very suitable for earthworks.

The most common type of defence used is the building of mounds, 4-6 m high, Io-1 $2 \mathrm{~m}$ wide, and $20-30 \mathrm{~m}$ long with a ditch dug in front. Such mounds have the effect of braking the avalanche flow and also of capturing snow on the uphill side. A second system is the terracing of slopes; beginning from the avalanche fracture line, earth is dug parallel to the contours. In two places dykes have been built to guide the snow, and in a few places avalanche sheds have been constructed, though because of expense these have been kept to a minimum. As the soil and climatic conditions are very suitable, tree planting around structures is a successful way of increasing avalanche protection.

During the analysis of effectiveness snow-fall as recorded was heavy, but the defences were effective and avalanches did not seriously interrupt the highway.

\title{
GEAR-TYPE GLIDE-METER AS AN INSTRUMENT FOR FORECASTING FULL-DEPTH AVALANGHES
}

\author{
By Yutaka Yamada \\ (Institute of Snow and Ice Studies, National Research Centre for Disaster Prevention, \\ Nagaoka, Niigata-ken, Japan 940)
}

Abstract. This paper is concerned with the variation of snow glide and its predictability in full-depth avalanches. From field measurements of snow glide using a newly developed gear-type glide-meter which is fixed to the ground and which measures the amount of glide as the angle of rotation of a gear, the following characteristics are deduced: (I) the variation of gliding rate is composed of both short-term and long-term variations, and (2) the existence of correlation between the short-term variation and the relative frequency of avalanches is recognized. 